\title{
Grand opportunities in plant science to address the grand challenges facing the planet
}

\section{Wolf B. Frommer*}

Department of Plant Biology, Carnegie Institution for Science, Stanford, CA, USA

*Correspondence: wfrommer@carnegiescience.edu

For people, plants can seem like aliens. Movements are typically slow, and many consider plants "slow and low life [sLow life]" (Hangarter, 2009). Their appearance and behavior are so different from ourselves that we are in awe when we learn that many of the central functions of plants and humans are encoded by highly conserved genes. For example at the core of metabolism, hexokinase, the enzyme that phosphorylates incoming glucose, and many of the proteins that transport glucose look strikingly similar. This similarity goes yet deeper, as hexokinase has two distinct functions both as an enzyme and as a sensor ("sensyme"), a duality that appears to be conserved from plants to fungi to animals (Frommer et al., 2003). In a second example, the identification of the first higher plant ammonium transporter allowed a function to be assigned for the first time to an important human locus - the Rhesus factor (Ninnemann et al., 1994; Marini et al., 1997). One of the most recent and striking examples of functional similarities was the finding that both plants and animals use carbonic anhydrase to sense carbon dioxide - in humans permitting champagne bubbles to be tasted, and in plants crucial for control over the gas exchange with the atmosphere (Frommer, 2010). McGary (2010) found that plants and people share at least 48 functional modules; sets of genes that act in common to produce a phenotype. Many of these are disease-related. "There was a lot of screaming in the halls for that one [sic what was conceived as unexpected similarity]" as Edward Marcotte, a cancer researcher at the University of Texas, stated in the New York Times (Zimmer, 2010). This "deep homology" in functional networks, identified through the use of large datasets from the TAIR Arabidopsis database (www.arabidopsis.org/) argues strongly that research in plants can not only unravel the secrets of plants, but can guide research in metazoan organisms. It is apparently a consequence of evolution, where much remains to be learned about the first ancestors of multicellular green organisms and the mechanisms that had to evolve to allow for efficient photosynthesis, gas exchange, efficient mining of mineral nutrients and multicellularity.

While most animals are motile and can move to new locations to acclimate to a changing environment, most plants will live their lives at the site of their "cradle," i.e., where the seed germinated. This adaptation has resulted in an extraordinary plasticity for acclimation to changing environments. For example trees in Siberia experience exceptionally low temperatures during winter from which they cannot escape. How is the survival of trees for decades possible in such conditions? Perhaps even more surprising is how plants can survive for many years in one spot while acquiring the right amounts of all mineral nutrients from the soil, a seeming conundrum since acquisition of either too little or too much of a given nutrient will cause damage and eventually death. This becomes a special mystery if we consider that some plants, such as Pinus longaeva survive for up to 5000 years at the site of "birth." How do they manage to mine the soil in their local environment so effectively over such a long life? The extreme lifespan of this and other plants species, such as Sequoia raises a further question, namely how have they fended off pathogens and diseases over such a long period without a "metazoan style" immune system?

Another major difference to humans is that plants do not share a classical neuronal system (Alpi et al., 2007). While plants are probably not intelligent, as had been suggested by the Nobel prize winner Maurice Maeterlinck at the turn of the 19th century (Maeterlinck, 2007), they must have evolved complex decision mechanisms and computational capabilities as well as unique tools and functions to be able to live as individuals under extreme conditions over long periods of time. The extraordinary capability to mine for nutrients requires, besides local computation, e.g., in the root, also integration of information across the whole plant, with communication along the vascular system, an area still marginally understood. Whether there are more fundamental differences in the physiology of animals and plants remains to be seen.

So what are the grand opportunities and challenges in plant physiology? We can look at this from two perspectives: the grand opportunities for biological discovery and the grand challenges posed by the status of our planet, i.e., the explosive growth of the human population and its consequences, the food and climate crises. While research in plant physiology can contribute to our overall understanding of biology due to the high conservation of mechanisms and modules across organisms, there are many plant-specific functions not conserved in animals. The most obvious is photosynthesis, of which much remains to be discovered especially regarding the regulation of this dangerous play with radicals. Another major challenge concerns the nature of plasmodesmata (Lucas et al., 2009), the unique cell-cell bridges connecting plant cells. It is still a mystery how plasmodesmata work, how they evolved, what they traffic or how they are controlled. In fact, we still lack knowledge of their basic components or the mechanisms required to coordinate "drilling" activities from two adjacent cells when plasmodesmata are formed secondarily (Kollmann and Glockmann, 1991). Also, the plant cell wall, synthesized by hundreds of enzymes and its three-dimensional structure is still not understood (Somerville, 2006), neither from a standpoint of structure nor function, e.g., in defense (Hematy et al., 2009). Plants are masters in chemistry, - they have been known for a long time to produce an immense variety of compounds using extensive networks of specialized metabo- 
lism (DellaPenna and Last, 2008). These compounds probably play a major role in interactions with herbivores and pathogens, e.g., the generation of volatiles to fend off foes and to attract helpers (Pichersky et al., 2006; Unsicker et al., 2009). Such systems are being used in Africa to protect corn against corn borers and witchweed (Striga) infection (Hassanali et al., 2008). This list of mysteries can be continued, however here, the examples presented above should suffice to highlight the scientific excitement and potential as well as the urgent need for future research in the field of plant function (physiology).

One of the most exciting frontiers in plant physiology is the extensive network of plant roots and their interaction with the soil (rhizosphere). To be able to survive in one spot, plants must be Senseis, Masters in the art of mining for minerals. They must have efficient recognition systems to detect gradients in nutrients and measure both internal and external levels continuously. To be able to mine the soil efficiently, roots must process many kinds of information, such as location of mineral nutrients in their immediate environment, the availability of carbohydrates supplied by the shoot, the direction of light, gravity, oxygen and redox gradients, $\mathrm{pH}$, and osmotic conditions etc (Vitha et al., 2000). The interplay of this myriad of cues regulates root chemotaxis, architecture, and function, i.e., the activity of transporters and metabolic pathways in the root. Drew (1975) demonstrated the localized effect of a variety of individual nutrients on root architecture. Today we do not know much more beyond the fact that plants respond to local nutrient levels, and still need to discover the root sensors (apart from the recent identification of a nitrate transceptor, Ho et al., 2009), the signaling networks and the computational processes involved in prioritization of cues (Drew, 1975).

Another frontier in this context is the interface of the plant and soil microbes (Bisseling et al., 2009), probably of similar importance for plants as the indigenous microbiota of humans (Todar, 2008). Mycorrhiza and Rhizobia are well known symbionts of plants; we know less about the many microbes, the dynamics of their populations and their contribution to the physiology of plants.
New research frontiers are currently being opened by novel technologies. New tools, i.e., the metagenomic analysis of the rhizosphere promises new insights into whether and how the soil microbiota contribute to nutrient mining and pathogen defense. Confocal microscopy now allows us to observe individual protein complexes moving in the cell, thereby creating a new field of microscopic enzymology (Gutierrez et al., 2009). Light microscopy has broken Abbe's law, providing resolution of biological structures down to almost the molecular scale (Huang, 2010). Signaling molecules, signaling processes, ions, and metabolites as well as their fluxes can be determined with subcellular resolution in real time (Frommer et al., 2009). Using these tools, we are now in a position to analyze processes such as chemotaxis in plant roots with subcellular precision, which will provide us with a whole new understanding of root growth, development and mining activity. Microfluidic devices and novel "root/soil observatories" in conjunction with genetic approaches are expected to have major impact on how we will analyze plant environment interactions (Maier et al., 2010).

From a genomics perspective, a major challenge is the assignment of functions to genes. Due to limited funding, no function has yet been assigned to the majority of plant genes. We thus need a surge in support and in large-scale post-genome projects, such as proteomics, associomics, and metabolomics, combined with bioinformatic approaches that can identify candidate functions based on guilt by association (Lee et al., 2010). More and more large-scale datasets are becoming available, such as protein interaction networks and phosphoproteomic information and many remain to be performed, such as maps of subcellular localization of proteins. The ultimate challenge will be to assemble the "parts" and their interactions into networks, to create models of the cellular and organismal processes and to use these network models to predict behavior under new challenges or the results of engineering. The integration of these data, as promised by Systems Biology, will be a major step towards Synthetic Biology.

In addition, there are practical grand challenges; many of which have remained the same over decades. How can we opti- mize photosynthesis (Long et al., 2006; Zhu et al., 2008)? Increase crop yields? Improve nutrient and water use efficiency? Increase tolerance to abiotic stresses? Increase resistance of plants to herbivores pathogens? Transfer $\mathrm{N}_{2}$-fixation into non-legume plants? A century ago, the photosynthesis researcher Giacomo Ciamician framed a vision for the future that relies on plants ("The Photochemistry of the Future"), this vision presents as grand an opportunity and a challenge today as it did a century ago (Ciamician, 1912).

\section{REFERENCES}

Alpi, A., Amrhein, N., Bertl, A., Blatt, M. R., Blumwald, E., Cervone, F., Dainty, J., De Michelis, M. I., Epstein, E., Galston, A. W., Goldsmith, M. H., Hawes, C., Hell, R., Hetherington, A., Hofte, H., Juergens, G., Leaver, C. J., Moroni, A., Murphy, A., Oparka, K., Perata, P., Quader, H., Rausch, T., Ritzenthaler, C., Rivetta, A., Robinson, D. G., Sanders, D., Scheres, B., Schumacher, K., Sentenac, H., Slayman, C. L., Soave, C., Somerville, C., Taiz, L., Thiel, G., and Wagner, R. (2007). Plant neurobiology: no brain, no gain? Trends Plant Sci. 12, 135-136.

Bisseling, T., Dangl, J. L., and Schulze-Lefert, P. (2009). Next-generation communication. Science 324, 691.

Ciamician, G. (1912). The photochemistry of the future. Science 36, 385-394.

DellaPenna, D., and Last, R. L. (2008). Perspective genome-enabled approaches shed new light on plant metabolism. Science 320, 479-481.

Drew, M.C. (1975). Comparison of the effects of a localized supply of phosphate, nitrate, ammonium, and potassium on the growth of seminal the root system and the shoot of barley. New Phytol. 75, 479-490.

Frommer, W. B., Schulze, W. X., and Lalonde, S. (2003). Hexokinase, Jack-of-all-trades. Science 300, 261-263.

Frommer, W. B. (2010). Biochemistry. $\mathrm{CO}_{2}$ mmon sense. Science 327, 275-276.

Frommer, W. B., Davidson, M. W., and Campbell, R. E. (2009). Genetically encoded biosensors based on engineered fluorescent proteins. Chem. Soc. Rev. 38, 2833-2841.

Gutierrez, R., Lindeboom, J. J., Paredez, A. R., Emons, A. M., and Ehrhardt, D. W. (2009). Arabidopsis cortical microtubules position cellulose synthase delivery to the plasma membrane and interact with cellulose synthase trafficking compartments. Nat. Cell Biol. 11, 797-806.

Hangarter, R. (2009). sLowlife: plants in motion. Chem. Herit. Mag. 27 accessed at www.chemheritage.org/ pubs/ch-v27n1-articles/feature_slowlife.html.

Hassanali, A., Herren, H., Khan, Z. R., Pickett, J. A., and Woodcock, C. M. (2008). Integrated pest management: the push-pull approach for controlling insect pests and weeds of cereals, and its potential for other agricultural systems including animal husbandry. Philos. Trans. R. Soc. Lond., B, Biol. Sci. 363, 611-621

Hematy, K., Cherk, C., and Somerville, S. (2009). Hostpathogen warfare at the plant cell wall. Curr. Opin. Plant Biol. 12, 406-413. 
Ho, C. H., Lin, S. H., Hu, H. C., and Tsay, Y. F. (2009) $\mathrm{CHL} 1$ functions as a nitrate sensor in plants. Cell 138 , 1184-1194.

Huang, B. (2010). Super-resolution optical microscopy: multiple choices. Curr. Opin. Chem. Biol. 14, 10-14.

Kollmann, R., and Glockmann, C. (1991). Studies on graft unions. III. On the mechanism of secondary formation of plasmodesmata at the graft interface. Protoplasma 165, 71-85.

Lee, I., Ambaru, B., Thakkar, P., Marcotte, E. M., and Rhee, S. Y. (2010). Rational association of genes with traits using a genome-scale gene network for Arabidopsis thaliana. Nat. Biotechnol. 28, 149-156.

Long, S. P., Zhu, X. G., Naidu, S. L., and Ort, D. R. (2006). Can improvement in photosynthesis increase crop yields? Plant Cell Environ. 29, 315-330.

Lucas, W. J., Ham, B. K., and Kim, J. Y. (2009). Plasmodesmata - bridging the gap between neighboring plant cells. Trends Cell Biol. 19, 495-503.

Maeterlinck, M. (2007). L'Intelligence des fleurs. State University of New York Press.

Maier, M., Lucchetta, E. M., and Ismagilov, R. F. (2010). Chemical stimulation of the Arabidopsis thaliana roo using multi-laminar flow on a microfluidic chip. Lab Chip (in press).

Marini, A. M., Urrestarazu, A., Beauwens, R., and André, B. (1997). The Rh (rhesus) blood group polypeptides are related to $\mathrm{NH}_{4}^{+}$transporters. Trends Biochem. Sci. $22,460-461$.

McGary, K.L., McGarya, K. L., Parka, T. J., Woods, J.O., Cha H. J., Wallingford, J. B., and Marcottea, E. M. (2010). Systematic discovery of nonobvious human disease models through orthologous phenotypes. Proc. Natl. Acad. Sci. USA 107, 6544-6549.

Ninnemann, O., Jauniaux, J. C., and Frommer, W. B. (1994). Identification of a high affinity $\mathrm{NH}_{4}^{+}$transporter from plants. EMBO J. 13, 3464-3471.

Pichersky, E., Noel, J. P., and Dudareva, N. (2006). Biosynthesis of plant volatiles: nature's diversity and ingenuity. Science 311, 808-811.

Somerville, C. (2006). Cellulose synthesis in higher plants. Annu. Rev. Cell Dev. Biol. 22, 53-78.

Todar, K. (2008). “The normal bacterial flora of humans," in Todar's Online Textbook of Bacteriology, ed. K. Todar (www.textbookofbacteriology.net).

Unsicker, S. B., Kunert, G., and Gershenzon, J. (2009). Protective perfumes: the role of vegetative volatiles in plant defense against herbivores. Curr. Opin. Plant Biol. 12, 479-485.

Vitha, S., Zhao, L., and Sack, F. D. (2000). Interaction of root gravitropism and phototropism in Arabidopsis wild-type and starchless mutants. Plant Physiol. 122, 453-461.

Zhu, X. G., Long, S. P., and Ort, D. R. (2008). What is the maximum efficiency with which photosynthesis can convert solar energy into biomass? Curr. Opin. Biotechnol. 19, 153-159.

Zimmer, C. (2010). The search for genes leads to unexpected places. NY Times. 04/17/2010, D1.

Received: 21 May 2010; accepted: 25 May 2010; published online: 14 June 2010.

Citation: Frommer WB (2010) Grand opportunities in plant science to address the grand challenges facing the planet. Front. Plant Sci. 1:11. doi: 10.3389/fpls.2010.00011 Copyright (C) 2010 Frommer. This is an open-access article subject to a non-exclusive license between the authors and Frontiers Media SA, which permits use, distribution and reproduction in other forums, provided the original authors and source are credited and other Frontiers conditions are complied with. 